\title{
Optimal Allocation Of Training Resources
}

\author{
Nasreddine Saadouli, American University in Dubai, United Arab Emirates
}

\begin{abstract}
Training is a key task for ensuring that employees remain at a skill level that is conducive to productivity and to achieving the organizational objectives. However, training is a very costly investment. Hence, the resources allocated to training must be used wisely to balance the available resources to the goals sought. In this paper, a typical training decision is considered where the management needs to decide on assigning employees at various levels of the organization to various training programs. This is to be done with minimal interruption of the organization's operations while making sure that the different types of employees are assigned to training programs most related to their jobs. Additionally, there is a limit on the capacity of the training facility and the number of trainers which in turn limits the number of training courses that can be offered in any given week. A linear programming model is developed to determine the optimal number of trainees that should be chosen from each department and the optimal allocation of these trainees to the various training courses. The model is applied to a real life situation and the results show that there is an optimal allocation that meets and in most cases exceeds the desired objectives of management while maximizing the utilization of the training resources.
\end{abstract}

Keywords: Human Resources; Training; Optimization; Linear Programming

\section{INTRODUCTION}

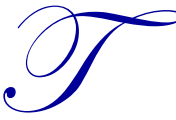

raining is a critical component of employees' development. It plays a crucial role in maintaining and improving their productivity and contributes significantly to enhancing their skills. Companies around the World have accepted this fact and started allocating significant funds to the training budget. Kauffeld et al. (2010) indicate that the average US Company spends about $\$ 955$ per employee on training. Furthermore, total training costs in the European Union ranged from $1.2 \%$ to $3.6 \%$ of overall labor cost in 1999. For this investment to be effective, managers need to allocate the scarce funds to achieve maximum returns. The issue of deciding how to assign the employees to the various training programs stands out. This is a complex problem due to the fact that training must be carried out without major disruption to the organization's operations. Additionally, there are various categories of employees within the organizational structure that may require different training programs, which may overlap with the training needs of the other categories. The capacity limits of the training programs coupled with the time limits within which training could be carried out further complicates the problem. There are many tradeoffs that managers need to take into account necessitating the use of mathematical models to help with the problem solution. Mathematical programming offers such capabilities. This has been pointed out as early as 1964 in (Smith 1964). Within specified constraints, linear programs could be formulated to achieve the optimal objective. In this paper, a linear program is formulated to help management decide on how to allocate employees at various managerial and clerical levels to training programs that have a limited capacity. The constraints also include a maximum number of employees at any level that could be in a training program to minimize disruption to their respective departments' business. Additionally, the senior management has stated certain guidelines on what proportion of each category should receive training relative to each training course offered.

Although the results of the investments in training are quite challenging to show as argued in Pienda (2010), the benefits of training have been well established. Training can lead to substantial cost savings. Merrick et al. (2006) report annual savings of over $\$ 2$ million in a financial corporation as a result of only three training courses in forecasting, optimization and simulation. Similarly, Sohoni et al. (2003) report expected savings of over $\$ 7.5$ million in the annual operating costs of a major airline as a result of using an automated optimization system to 
schedule continuing qualification training for pilots. Furthermore, training subsidies reduce unemployment while increasing wages and training incidence, and that less generous unemployment benefits typically increase training incidence (Menezes and Vieira 2008).

Training is also a significant investment to the organization. The need to optimize the use of these resources is becoming even more pressing due to the increased competition and scarcity of qualified labor. On one hand, training reduces turnover (Munasinghe and O'Flaherty 2005); on the other hand, investing in training employees represents a challenge to the organization as it may provide the employees with the desired skills for them to be headhunted by rivals (Finegold and Wagner 2002). The training and development process which includes needs assessment and developing training programs grows more challenging with the size of the firm and the time compression characterizing today's economic environment. Kuprenas et al. (1999) report on the challenges faced, the solutions formulated and the lessons learned in managing the logistics of training for a large number of trainees in a short period of time. In evaluating training programs, Ryan (1998) highlights the importance of giving critical consideration to four key criteria: compatibility, optimization, wholeness, and systemization. The application of optimization techniques, such as operational research (OR) methods, to the allocation of resources was introduced in the early 1970s. McNamara (1971) developed a linear program to aid state planners efficiently allocate vocational education funds to local school districts. Balinsky and Reisman (1972) developed dynamic programs to determine the optimal number of entrants into a training program in a given period. Ladany (1975) used linear programming to maximize the performance of an athlete subject to training and physiological requirements for balancing the development of the athlete's body. These early models presented a stepping stone for developing much more complex models that attempt to capture the many interdependencies in the problem while capitalizing on the growing base of computer and algorithmic developments. Although early models mostly relied on linear programming, researchers have recently turned to other mathematical programming techniques. Giannikos and Polychroniou (2009) used a fuzzy goal programming model to allocate tasks to employees in teamwork while considering the possibility of improving their abilities through training. Juang et al. (2007) developed an optimal curriculum arrangement model in maintenance personnel training programs and utilized genetic algorithms as a solution procedure. They also developed an adaptive computer-aided training system for maintenance representatives to facilitate personnel training for the machine tool industry. Zwols and Sierksma (2009) developed a mathematical mode (a nonlinear optimization model) to optimize the use of the total available training time by assigning time to training exercises. Fan and $\mathrm{Wu}$ (2008) used an analytic hierarchy process method to optimally select training programs for sales representatives resulting in overhead cost reduction and a better understanding of the necessary competences. Heuristic methods have also been employed to schedule training programs as in Rezaei et al (2012) to determine the optimal scheduling of training programs.

In section 2, the model is introduced and its various components are analyzed. In section 3 , the solution methodology is discussed. In section 4, a real life case study is presented and the solution is analyzed. The exposition concludes with a recap of the key findings and a statement of the future research.

\section{TRAINING COURSES ALLOCATION MODEL}

Organizations continuously invest in training to enhance service quality levels and hence maintain longer and more profitable relationships with their customers. There are several levels of employees that are eligible for training, hereon denoted by $M$. Furthermore, there are several training courses that are available, which we shall denote by $C$. The management needs to decide on how many employees of a given level to assign to any one of the training courses in any given week of the year. The decision variable is thus defined as $x_{m c w}, m=1 \ldots M, c=$ $1 \ldots C, w=1 \ldots 52$.

\subsection{Model Constraints}

The first constraint is the class capacity constraint. All classes' capacities are defined on a weekly basis since no training program would take more than one week. The maximum number of participants in class $j$ in a given week $k$ should not exceed the class capacity $M A X C A P_{c w}$ regardless of the category of the employee. The constraint is stated as follows: 


$$
\sum_{m=1}^{M}\left(x_{m c w}\right) \leq M_{A X C A P} c w ; \forall c=1 \ldots C ; \forall w=1 . .52
$$

To ensure that the various departments continue operating with minimal disruption, a maximum number of participants from the department (level) is set and denoted by MAXPART $m w$. This must hold regardless of what courses the participants are attending. The constraint can formally be stated as follows:

$$
\sum_{c=1}^{C}\left(x_{m c w}\right) \leq M A X P A R T_{m w} ; \forall m=1 \ldots M ; \forall w=1 . .52
$$

To ensure the training effectiveness throughout the organization and to ensure that sufficient proportions of employees in a given level get the most appropriate training courses, a minimum number of employees from each category must participate in any given training course. Let $M I N P A R T_{m c}$ denote the minimum number of employees of level $m$ that must participate in course $c$ by year end. The constraint can therefore be stated as follows:

$$
\sum_{w=1}^{52}\left(x_{m c w}\right) \geq M I N P A R T_{m c} ; \forall m=1 \ldots M ; \forall c=1 . . C
$$

Obviously, the number of participants in all training programs from any category during a period of one year cannot exceed the number of employees in that category. Let $P O P_{m}$ denote the total number of employees in category $m$. This translates to the following constraint:

$\sum_{c=1}^{C} \quad \sum_{w=1}^{52}\left(x_{m c w}\right) \leq P O P m ; \forall m=1 \ldots M$

\subsection{Objective Function}

Determining the return from training has consistently remained a thorny issue in managing training programs allocation. In some instances, the issue could simply be minimizing the total cost of the program. However, in our case, the training courses have already been decided upon as well as the necessary resources for running the courses. The issue is more on how to make sure that the allocation of the employees to the courses yields improvements in the organization's operations. In this general statement of the problem, let's simply denote the return by $R_{m c}$, meaning that this would be the anticipated benefit to the company if one employee from category $m$ takes course $c$. The objective would therefore be to maximize such return.

$\max \sum_{m=1}^{M} \sum_{c=1}^{C} \sum_{w=1}^{52} R_{m c} x_{m c w}$ 
With this definition of the objective function, the model is complete. The linear program is thus formulated as follows:

$\max \sum_{m=1}^{M} \sum_{c=1}^{C} \sum_{w=1}^{52} R_{m c} x_{m c w}$

s.t

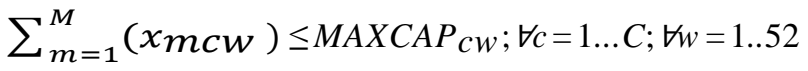

$\sum_{c=1}^{C}\left(x_{m c w}\right) \leq M A X P A R T_{m w} ; \forall m=1 . . . M ; \forall w=1 . .52$

$\sum_{w=1}^{52}\left(x_{m c w}\right) \geq M I N P A R T_{m c} ; \forall m=1 . . . M ; \forall c=1 . . C$

$\sum_{c=1}^{C} \quad \sum_{w=1}^{52}\left(x_{m c w}\right) \leq P O P_{m} ; \forall m=1 \ldots M$

$x_{m c w} \geq 0 ; \forall m=1 \ldots M ; \forall c=1 \ldots C ; \forall w=1 \ldots 52$ presented.

In the following section, the model is applied to a basic real life case and the solution procedure is

\subsection{Case Data}

\section{MODEL APPLICATION AND SOLUTION}

The model is applied to a company in the United Arab Emirates. The company has 5 categories of employees that are eligible for training, i.e. $M=5$. The various categories are presented in Table 1 . The table also indicates the total number of employees in each category $P O P_{m}$ and the maximum number of participants in a training course in any given week $M A X P A R T_{m w}$, which is simply $5 \%$ of the total number of employees in that category in this case.

Table 1: Employees Categories Summary

\begin{tabular}{lcc}
\hline \multicolumn{1}{c}{ Category } & Total Number & MAXPART \\
\hline Higher Management (HM) & 300 & 15 \\
\hline Middle Management (MM) & 700 & 35 \\
\hline Customer Service Officer (CSO) & 800 & 40 \\
\hline Customer Service Representative (CSR) & 2200 & 110 \\
\hline Courier (CO) & 1000 & 50 \\
\hline Sum & 5000 & 250 \\
\hline
\end{tabular}

The company has invested in a new training facility that has six training rooms, hence in any given week, a maximum of 6 training courses could be carried out simultaneously, i.e. $C=6$. Some of the courses are 2-day courses and could be run twice a week; whereas others are 5-day courses and could be run only once a week. The six courses and the respective class capacities are presented in Table 2 . The table also provides the minimum number of participants from a category in that course during a period of one year, i.e. MINPART $m c$.

Table 2: Training Courses Summary

\begin{tabular}{|c|c|c|c|c|c|c|}
\hline \multirow[t]{2}{*}{ Course } & \multirow[t]{2}{*}{ Weekly Capacity } & \multicolumn{5}{|c|}{ MINPARTmc } \\
\hline & & HM & MM & CSO & CSR & $\mathrm{CO}$ \\
\hline Customer Relationship Management I & 30 & & & 240 & 880 & 300 \\
\hline Customer Relationship Management II & 30 & & 280 & 400 & 440 & \\
\hline Information Technology I & 15 & & 140 & 160 & 440 & \\
\hline Information Technology II & 15 & 150 & 350 & & & \\
\hline Managerial Course & 15 & 150 & 280 & 160 & & \\
\hline Postal General Course & 15 & & & & 800 & \\
\hline Sum & 120 & 300 & 1050 & 1760 & 1760 & 300 \\
\hline
\end{tabular}




\subsection{Case Model}

For the case at hand, the primary purpose of the management is to ensure that the maximum number of employees across all employment levels take the training courses while maintaining the ongoing operation of the organization. To this effect, the objective function is to maximize the total number of participants in all relevant training courses. As such, there's no attempt at this stage to quantify the returns the organization would anticipate from the training courses. The constraints ensure that course capacities are not exceeded, that the minimum and maximum number of participants in a single course are maintained, and that the total number of participants from any category does not exceed the total number of employees in that category. Consequently, the linear program specific to the case presented can be stated as follows:

$$
\begin{gathered}
\max \sum_{m=1}^{5} \sum_{c=1}^{6} \sum_{w=1}^{52} x_{m c w} \\
\sum_{m=1}^{5}\left(x_{m c w}\right) \leq \text { MAXCAP }_{c w} ; \forall c=1 \ldots 6 ; \forall w=1 . .52 \\
\sum_{c=1}^{6}\left(x_{m c w}\right) \leq M A X P A R T_{m w} ; \forall m=1 \ldots 5 ; \forall w=1 . .52 \\
\sum_{w=1}^{52}\left(x_{m} c w\right) \geq M I N P A R T_{m c} ; \forall m=1 \ldots 5 ; \forall c=1 . .6 \\
\sum_{c=1}^{C} \quad \sum_{w=1}^{52}\left(x_{m c w}\right) \leq P O P_{m} ; \forall m=1 \ldots 5 \\
x_{m c w} \geq 0 ; \forall m=1 \ldots 5 ; \forall c=1 \ldots 6 ; \forall w=1 . .552
\end{gathered}
$$

\subsection{Solution Procedure}

The linear program developed is of a fairly moderate size (1560 variables and 607 constraints in addition to the non-negativity constraints). It was solved using a commercially available spreadsheet-based linear programming solver. Using a spreadsheet-based solver is quite effective in generating a solution that is well organized for decision makers to investigate. Seeing the actual assignment of the number from each category to each course on a weekly basis presented the management with a visual framework for understanding the solution and eventually converting it to training schedules. Solver found an optimal solution in 1.29 seconds for this case.

\section{RESULTS ANALYSIS}

The solved model yields important results and enables the management to have key insights into this complex problem. Table 3 summarizes the main findings from the model in terms of the total yearly numbers of trainees. All employees in the various categories have been assigned to appropriate training courses while keeping the departments operational. For the test case data, the decision makers have also an indication of the number of cycles (years) that would be required to have all eligible employees trained. With the sensitivity analysis, the decision makers can gain insight into the value of adding resources if the training cycle is deemed too long. Essentially, they can balance the benefit of appropriating additional funds to training to the expected improvement in performance resulting from training. This is quite important to maintain the senior management's support of the training efforts since this is done without disruption of the organization's business. Furthermore, it is interesting to see that the assignments are balanced among the various employee categories. This ensures that the reduction in the number of working personnel due to participation in training programs does not lead to developing bottlenecks where certain departments are significantly more staffed than others. The model also provides a weekly schedule of the allocation of the trainees from various organizational levels to the different training courses. 
Table 3: Total Yearly Summary

\begin{tabular}{lccccc}
\hline Department & $\begin{array}{c}\text { Total } \\
\text { Trainees/year }\end{array}$ & Dep. Total & Total Potential & \% Trained & $\begin{array}{c}\text { \# Cycles } \\
\text { Needed (years) }\end{array}$ \\
\hline HM & 450 & 300 & 600 & 75 & 1.33 \\
\hline MM & 1560 & 700 & 2800 & 46 & 1.73 \\
\hline CSO & 1950 & 800 & 4000 & 59 & 2.05 \\
\hline CSR & 1980 & 2200 & 6600 & 30 & 3.33 \\
\hline CO & 300 & 1000 & 1000 & 30 & 3.33 \\
\hline
\end{tabular}

\section{CONCLUSION}

In this paper, the problem of optimally assigning employees at various organizational levels to training programs is addressed. In light of the restrictions on the training courses capacities, the allowable number of trainees from each level and the need to maximize the utilization of the training resources, a linear program is developed and solved on a real life case. The model's key contribution is its general nature and ease of implementation. These characteristics are invaluable for a decision maker with little mathematical knowledge and a need for quick and inexpensive solutions. The main limitation of the model is the challenge of determining the expected benefit of the training programs on organizational performance, which is a challenge common to this field (Pienda, (2010), Kuprenas et al. (1999),...etc.). The model can be become more realistic by taking into account the stochastic nature of the availability of the training resources and the generalization of the objective to include the anticipated benefits of such programs. These venues, and others, are being considered by the author for future research initiatives.

\section{AUTHOR INFROMATION}

Nasreddine Saadouli has rejoined AUD as an associate professor of Management since September 2014. He was an associate professor of management at the Gulf University for Science and Technology (GUST) in Kuwait from September 2005 till August 2013 where he also served as the Head of the Department of Business Administration from October 2009 till September 2012.

Dr. Saadouli earned his Ph.D.and M.Sc. in Management Science and B.Sc. in Business Management from the University of Tennessee in Knoxville. He graduated with a Summa Cum Laude and was consistently on the Dean's list for outstanding students.

\section{REFERENCES}

Balinsky, W. and Reisman, A. (1972). Some Manpower Planning Models Based on Levels of Educational Attainment. Management Science, Application Series, 18(12), B691-B705.

Fan, C-K. and Wu, C-R. (2008). optimal Selection of Training Program for Taiwanese Life Insurance Sales Representatives by using Analytic Hierarchy Process Method and Sensitivity Analysis. Journal of Information \& Optimization Sciences, 29(6), 11-41.

Finegold, D. and Wagner, K. (2002). Are Apprenticeships Still Relevant in the $21^{\text {st }}$ Century? A case Study for Changing Youth Training Arrangements in German banks. Industrial and Labor relations review, 55(4), 667-685.

Giannikos, I and Polychroniou, P. (2009). A Fuzzy Goal Programming Model for task Allocation in teamwork. International journal of Human Resources Development and Management, 9(1), 97-115.

Juang, Y-S, Lin, S-S and Kao H-P. (2007). An Adaptive Scheduling System with Genetic Algorithms for Arranging Employee Training Programs. Expert Systems with Applications, 33(3), 642-651.

Kauffeld S. and Lehmann-Willenbrock, N. (2010). Sales Training: Effects of Spaced Practice on Training Transfer. Journal of European industrial training, 34(1), 23-37.

Kuprenas, A., Madjidi F. and Stephen Alexander A. (1999). A Project Management training Pro- gram. Journal of Management in engineering, 15(6), 47-55.

Ladany, S. P. (1975). Optimization of Pentathlon Training Plans. Management Science, 21(10), 1144-1155.

McNamara, J. F. (1971). A Mathematical Programming Approach to State-local Program Planning in Vocational education. American Educational Research Journal, 8(2), 335-363. 
Merrick, A. R. W., Hardin, J. R. and Walker, R. (2006). Partnerships in Training. Interfaces, 36(4), 359-370.

Menezes, A. and Vieira, J. (2008). Training, Job Upgrading, Job Creation and Job Destruction. Atlantic Economic Journal, 36, 275-292.

Munasinghe, L. and O'Flaherty, B. (2005). Specific Training Sometimes Cuts Wages and Always Cuts Turnover. Journal of Labor Economics, 23(2), 213-233.

Pienda, P. (2010). Evaluation of Training in Organizations: A Proposal for an Integrated Model. Journal of European Industrial Training, 34(7), 673-693.

Rezaei, M., Shamsaei, F., Mohammadian, I. and Van-Vyve, M. (2012). A Heuristic Method to Schedule training Programs for Small and Medium Enterprises. European journal of Operational research, 217(3), $600-$

Ryan, T. A. (1998). Generic Model for Correctional Staff Training: Implications for Managers. Corrections Management Quarterly, 2(1), 74-82.

Smith A. (1964). Statistical training within an Industrial Firm. The American Statistician, 18(2), 22-24.

Sohoni, M. G., Bailey, T. G., Martin, K. G., carter, H. and Johnson, E. L. (2003). Delta Optimizes ContinuingQualification-Training Schedules for Pilots. Interfaces, 33(5), 57-70.

Zwols, Y.and Sierksma, G. (2009). Training Optimization for the Decathlon. Operations Research, 57(4), 812-822. 


\section{APPENDIX: Solution Summary by Course}

Table 4: Solution Summary

\begin{tabular}{|c|c|c|c|c|c|}
\hline Course & Department & \# Trainees/year & MINPART & Dep. Total & \% Trained \\
\hline \multirow{5}{*}{$\begin{array}{l}\text { Customer Relationship } \\
\text { Management I }\end{array}$} & HM & 0 & 0 & 300 & \\
\hline & $\mathrm{MM}$ & 0 & 0 & 700 & \\
\hline & $\mathrm{CSO}$ & 380 & 240 & 800 & 48 \\
\hline & CSR & 880 & 880 & 2200 & 40 \\
\hline & $\mathrm{CO}$ & 300 & 300 & 1000 & 30 \\
\hline \multirow{5}{*}{$\begin{array}{l}\text { Customer Relationship } \\
\text { Management II }\end{array}$} & $\mathrm{HM}$ & 0 & 0 & 300 & \\
\hline & MM & 500 & 280 & 700 & 71 \\
\hline & $\mathrm{CSO}$ & 400 & 400 & 800 & 50 \\
\hline & CSR & 660 & 660 & 220 & 30 \\
\hline & $\mathrm{CO}$ & 0 & & 1000 & \\
\hline \multirow{5}{*}{ Postal General } & HM & 0 & 0 & 300 & \\
\hline & $\mathrm{MM}$ & 0 & 0 & 700 & \\
\hline & $\mathrm{CSO}$ & 0 & 0 & 800 & \\
\hline & CSR & 780 & 800 & 2200 & 35 \\
\hline & $\mathrm{CO}$ & 0 & 0 & 1000 & \\
\hline \multirow{5}{*}{$\begin{array}{l}\text { Information } \\
\text { Technology I }\end{array}$} & $\mathrm{HM}$ & 0 & 0 & 300 & \\
\hline & MM & 180 & 140 & 700 & 26 \\
\hline & $\mathrm{CSO}$ & 160 & 160 & 800 & 20 \\
\hline & CSR & 440 & 440 & 2200 & 20 \\
\hline & $\mathrm{CO}$ & 0 & & 1000 & \\
\hline \multirow{5}{*}{$\begin{array}{l}\text { Information } \\
\text { Technology II }\end{array}$} & HM & 300 & 150 & 300 & 100 \\
\hline & MM & 480 & 350 & 700 & 69 \\
\hline & $\mathrm{CSO}$ & 0 & & 800 & \\
\hline & CSR & 0 & & 2200 & \\
\hline & $\mathrm{CO}$ & 0 & & 1000 & \\
\hline \multirow{5}{*}{ Managerial Course } & $\mathrm{HM}$ & 150 & 150 & 300 & 50 \\
\hline & MM & 400 & 280 & 700 & 57 \\
\hline & $\mathrm{CSO}$ & 230 & 160 & 800 & 23 \\
\hline & CSR & 0 & & 2200 & \\
\hline & $\mathrm{CO}$ & 0 & & 1000 & \\
\hline
\end{tabular}

